\title{
Comparison of Shoulder Muscle Strength of Deaf and Healthy Basketball Players
}

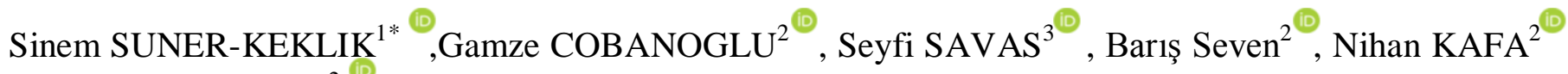 \\ and Nevin A. GUZEL ${ }^{2}$ \\ ${ }^{1}$ Sivas Cumhuriyet University, Faculty of Health Sciences, Department of Physiotherapy and Rehabilitation, Sivas, Turkey \\ ${ }^{2}$ Gazi University, Faculty of Health Sciences, Department of Physiotherapy and Rehabilitation, Ankara, Turkey \\ ${ }^{3}$ Gazi University, Faculty of Sports Science, Department of Physical Education and Sports Teaching, Ankara, Turkey \\ *Corresponding author: s-suner@hotmail.com
}

\begin{abstract}
Purpose: It has still not been made clear whether the audio inputs from the environment may have on the muscle strength characteristics of people who spend long periods of their lives with hearing loss. The purpose is to evaluate shoulder muscle strength and endurance of deaf basketball (DB) players and to compare them with healthy basketball (HB) players. Methods: The study was carried out with a total of 26-man players including 13 players (years: $24 \pm 3$ ) in DB group and 13 players (years: $22 \pm 2$ ) in HB group. Internal rotator (IR) and external rotator (ER) muscles strength of shoulder dominant and non-dominant side was measured using an isokinetic dynamometer. Results: According to isokinetic test results, there was not a difference between two groups on either dominant or nondominant side in terms of ER and IR Nm/kg (p>0.05). The ER / IR ratio was different between the two groups in favor of HB players $(\mathrm{p}=0.017)$. The strength parameters of dominant extremities of players in both groups were found to be higher than nondominant extremity. Conclusions: As a result, IR and ER muscle strengths were similar in two groups, both groups were at risk for musculoskeletal injuries in terms of ER/IR ratio. It could be speculated that it is essential to design training programs with additional ER strengthening exercises to improve the balance between IR and ER muscles and minimize risk of injury. The dominant extremity was found to be stronger in both groups. In our opinion, symmetrical movement patterns will positively affect performance on dominant extremity.
\end{abstract}

\section{Keywords}

Basketball, Deaf Player, Shoulder Muscle Strength

\section{INTRODUCTION}

Basketball is a physically challenging sport which involves defensive and offensive movements (Pojskić, Šeparović, Užičanin, Muratović, \& Mačković, 2015). Motoric and anthropometric features play an important role in achieving success in basketball. The sport of basketball requires strength, speed, flexibility, agility and endurance. The strength required for this sport is manifested in different forms such as maximal strength, agility (power) and endurance. Throwing power at offense passes at various positions, the arm strength during the jump from the three-point zone and the arm and leg strength at free throws are the most significant examples of this condition (Akçakaya, 2009).

Competitive sports for people with disabilities have entered a rapidly developing process in recent years (Akınoğlu \& Kocahan, 2017). Many individuals with disabilities from elite level professional athletes to recreational sports participants have been participating in these sports. It can, therefore, be said that sports are the healthiest way to improve their social integration by strengthening their self-confidence, self- 
efficacy and quality of life as well as contributing to the improvement of the fitness parameters such as cardio-metabolic fitness and flexibility (Akınoğlu \& Kocahan, 2017).

Deaf Basketball (DB) is played according to the rules of Healthy Basketball (HB), and each sport has similar physiological demands (Güzel \& Kafa, 2016). Those who have a hearing loss of at least $55 \mathrm{~dB}$ in the better ear are eligible for being an athlete and participating in the competition (Brancaleone, Shingles, \& DeLellis, 2017; Ross, Irrgang, Denegar, McCloy, \& Unangst, 2002). A deaf athlete must be physically strong and able to compete without significant limitations (Kurková, Válková, \& Scheetz, 2011). The strength of shoulder muscles and stabilization of these joints are substantially important for each of these two basketball groups who use upper extremity functions specific to basketball such as dribbling, lay-up and rebound (Berckmans et al., 2017).

External Rotators (ER) and Internal Rotators (IR) are responsible for the stabilization of the shoulders (Berckmans et al., 2017), and the muscular imbalance between these muscles is accepted as one of the factors that cause musculoskeletal dysfunction of the shoulder (Codine, Bernard, Pocholle, \& Herisson, 2005; Dauty et al., 2003; Dvir, 2004; Warner, Micheli, Arslanian, Kennedy, \& Kennedy, 1990). Overhead sports comprising repeated arm movements that require strength such as basketball, volleyball, baseball and handball cause increased shoulder injury incidences. Ballistic movements in such sports cause eccentric overload on the rotator cuff muscles which are prone to injury. Rotator cuff muscles are considered to be the most important dynamic stabilizers of the glenohumeral joint Weak rotator cuff muscles may lose the ability to maintain a balanced relationship with the antagonist's muscles as a result of micro-traumas caused by repetitive overhead movements. (Baltaci \& Tunay, 2004).

These strength imbalances in the muscles which make up the rotator cuff can render injuries caused by eccentric overload worse or may cause secondary impingements or instabilities. Because of the critical functional role of the rotator cuff muscles, objective evaluation of shoulder IR and ER strength is essential in pre-participation evaluations to prevent injuries and during the rehabilitation of the injured athlete (Baltaci \& Tunay, 2004). Because of its functional importance, the objective evaluation of the strength of ER and IR muscles is necessary to determine risk factors and prevent injuries. Many procedures such as manual muscle testing, hand dynamometers and isokinetic dynamometers are used in the evaluation of the shoulder strength. Isokinetic dynamometers are often used in the objective evaluation of muscle performance (Pascal Edouard et al., 2011).

Even though that the evaluation of the muscular performance of the upper extremity in sports such as basketball is considerably important for both determination of injury risk and elimination of deficiencies of the training program, such a study that evaluates the shoulder muscle strength of DB players has not been in studies. Moreover, it has still not been made clear what effects the audio inputs from the environment may have on the muscle strength on people who spend long periods of their lives with hearing loss despite the similarity of their physiological needs. The shoulder strength difference between DB and HB players has not been made clear yet, either. Therefore, this study aims to evaluate the shoulder muscle strength and endurance of the DB players and to compare these results with those of $\mathrm{HB}$ players.

\section{MATERIALS AND METHODS}

\section{Participants}

The study was done with 26 players, which included a group of 13 DB players and a group of $13 \mathrm{HB}$ players. It included individuals who were between the ages of 18-30 and have been actively involved in basketball for at least two years with no difference between their active sports year and weekly training frequency as well as agreeing to participate in the study. The study excluded those who had undergone upper extremity operation, those with neurological problems, systemic diseases and who had shoulder problems or shoulder pain in the last 3 months. In March 2018, individuals started to be evaluated. Prior to the study, the purpose and content of the study were made clear to the players and a Clarified Consent Form was signed regarding their voluntary participation. Ethics committee permission was obtained from the ethics committee of the university with the decision dated 06.02.2018 and numbered 77082166-302.08.01. 


\section{Procedures}

Players' age, height, body weight, BMI, dominant side, active sports year, weekly training time, history of any shoulder injury, background and family history were inquired and noted. Isokinetic systems are highly reliable for measurements at different positions and angular velocities (Brown, 2000). For this reason, they are frequently used to objectively evaluate the strength of rotator muscles (Ellenbecker \& Davies, 2000). Therefore, IR and ER muscle strength values were measured using an isokinetic dynamometer (Cybex NORM ${ }^{8}$, Humac, CA, USA). Isokinetic evaluations were performed in seated position with the arm in the scapular plane. The players were seated upright on the device and the stabilization of the body was achieved with horizontal and pelvic straps. The elbow was stabilized with a band. The assessment order was randomly decided for either shoulder.

The range of motion was determined as $50^{\circ}$ internal rotation and $40^{\circ}$ external rotation to prevent excessive movement of the shoulder joint. (Moraes, Faria, \& Teixeira-Salmela, 2008). Three submaximal repetitions at each angular velocity were done for warm-up and learning. Measurement of strength was performed in the concentric mode with 5 repetitions at an angular velocity of $60 \% \mathrm{sec}$, and endurance measurements with 15 repetitions at an angular velocity of $180^{\circ} / \mathrm{sec}$ (Pontaga \& Zidens, 2014). The subjects had 20 seconds of rest between trials and tests (warm-up and maximum measurement) and 90 seconds of rest between the sets.

Gravity compensation was turned on during the adjustment of the measurement parameters to improve the objectivity of the measurement. Before starting the measurement, the subject's arm was moved to neutral position in order to measure the weight of the subject and the device, thereby eliminating the effect of gravity during the test. Regardless of the hearing impairments of the players that form one of the two groups, the subjects in neither group were given any sort of verbal motivation, and the measurements were performed by the same person for objectivity. All measurements were repeated on the other extremity by changing the position of the dynamometer and seat. As a result of the test, peak torque of ER and IR were obtained at each angular velocity for each shoulder, and unilateral ER and
IR ratios for peak torque (ER/IR ratio) were calculated.

\section{Statistical Analysis}

The statistical analysis was performed using "Statistical Package for Social Sciences" (SPSS) Version 22.0 (SPSS Inc., Chicago, IL, ABD). The normal distribution of the data was analyzed using visual (histogram and probability graphs) and analytical methods (KolmogorovSmirnov/Shapiro-Wilk Test). The variables with no normal distribution were indicated with median and IQR (25-75) and categorical variables with frequency and percentage (\%). "Mann-Whitney U Test" was used to determine the difference between DB and HB players. The probability level of a type 1 error was accepted 5\% for statistical significance.

\section{RESULTS}

Demographic data of the subjects are given in Table 1 . There was not a statistically significant difference between the two groups in terms of age, body weight, height and body mass index (BMI). While there was no difference between DB and HB subjects in terms of active sports year and weekly training time, the age at which regular basketball players started the sport was found to be statistically significantly younger $(\mathrm{p}<0.05$, Table $1)$.

According to the isokinetic test results, there was not a difference between the two groups on either the dominant or non-dominant side at the angular velocity of $60 \% \mathrm{sec}$ and $180 \% \mathrm{sec}$ in terms of ER and IR Nm/kg and the ER/IR ratio at the angular velocity of $60 \% \mathrm{sec}(\mathrm{p}>0.05$, Table 2$)$, while there was a difference in terms of ratio on the dominant side in ER/IR at the angular velocity of $180^{\circ} / \mathrm{sec}(\mathrm{p}<0.05$, Table 2$)$. ER/IR ratio was found to be lower in the DB group.

Upon the examination on the difference between the dominant and non-dominant sides of DB players, it was determined that there was not a difference in terms of $60 \% \mathrm{sec}$ ER Nm/kg, $180 \% \mathrm{sec}$ ER-IR Nm/kg and ER/IR ratio ( $>0.05$, Table 3), whereas there was a difference in terms of $60 \% \mathrm{sec}$ IR $\mathrm{Nm} / \mathrm{kg}$ and ER/IR ratio ( $<<0.05$, Table 3 ). The strength on the dominant side was found to be higher than that of the non-dominant side in terms of $60 \% \mathrm{sec}$ IR $\mathrm{Nm} / \mathrm{kg}$. ER/IR ratio, however, was determined to be higher on the non-dominant side compared to the dominant side. 
Table 1. Demographic characteristics of players

\begin{tabular}{|c|c|c|c|}
\hline & DB (IQR) $(n=13)$ & HB (IQR) $(n=13)$ & $\mathbf{p}$ \\
\hline Age (years) & $23(21 / 26.5)$ & $22(21.5 / 23)$ & 0.496 \\
\hline Body weight (kg) & $82.2(79.2 / 91.6)$ & $92(85.5 / 97.5)$ & 0.069 \\
\hline Height (cm) & $183(180.5 / 192)$ & $192(184 / 202.5)$ & 0.057 \\
\hline BMI $\left(\mathrm{kg} / \mathrm{m}^{2}\right)$ & $24.53(22.24 / 26.26)$ & $24.96(23.04 / 25.27)$ & 0.750 \\
\hline Age of Starting the Sport (years) & $12(9 / 14)$ & $9(6.5 / 10.5)$ & 0.019* \\
\hline Active Sport Years (years) & $10(8.5 / 14.5)$ & $13(11.5 / 16)$ & 0.186 \\
\hline Weekly Training Time (hours) & $10(8 / 10)$ & $10(6.5 / 15)$ & 0.840 \\
\hline $\mathbf{R}$ & $13(100)$ & $13(100)$ & \\
\hline Dom, n (\%) & $0(0)$ & $0(0)$ & \\
\hline
\end{tabular}

Table 2. Shoulder strength and endurance of the DB and HB players

\begin{tabular}{|c|c|c|c|c|c|c|}
\hline & & \multicolumn{2}{|c|}{ DB $(n=13)$} & \multicolumn{2}{|c|}{ HB $(n=13)$} & \multirow[b]{2}{*}{$\mathbf{p}$} \\
\hline & & Median & IQR & Median & IQR & \\
\hline \multirow{6}{*}{ Dom } & $60^{\circ} / \mathrm{sec}$ IR $(\mathrm{Nm} / \mathrm{kg})$ & 63 & $58.5 / 66$ & 63 & $58.5 / 72$ & 0.815 \\
\hline & $60^{\circ} / \mathrm{sec}$ ER $(\mathrm{Nm} / \mathrm{kg})$ & 30 & $30 / 33$ & 36 & $27 / 40.5$ & 0.211 \\
\hline & $60^{\circ} / \mathrm{sec}$ ER/IR & 51 & $47 / 56$ & 55 & $41.5 / 64$ & 0.411 \\
\hline & $180^{\circ} / \mathrm{sec}$ IR $(\mathrm{Nm} / \mathrm{kg})$ & 51 & $48 / 57$ & 51 & $52 / 55.5$ & 0.365 \\
\hline & $180^{\circ} / \mathrm{sec}$ ER $(\mathrm{Nm} / \mathrm{kg})$ & 24 & $24 / 27$ & 27 & $22.5 / 33$ & 0.332 \\
\hline & $180^{\circ} / \mathrm{sec}$ ER/IR & 48 & $44.5 / 50$ & 56 & $49 / 66$ & 0.017* \\
\hline \multirow{6}{*}{ Non-dom } & $60^{\circ} / \mathrm{sec}$ IR $(\mathrm{Nm} / \mathrm{kg})$ & 57 & $54 / 61.5$ & 57 & $49.5 / 64.5$ & 0.979 \\
\hline & $60^{\circ} / \mathrm{sec}$ ER $(\mathrm{Nm} / \mathrm{kg})$ & 33 & $28.5 / 33$ & 33 & $27 / 37.5$ & 0.815 \\
\hline & $60 \%$ sec ER/IR & 56 & $49.5 / 58$ & 53 & $48 / 61$ & 0.644 \\
\hline & $180^{\circ} / \mathrm{sec}$ IR $(\mathrm{Nm} / \mathrm{kg})$ & 54 & $45 / 57$ & 42 & $37.5 / 51$ & 0.127 \\
\hline & $180^{\circ} / \mathrm{sec}$ ER $(\mathrm{Nm} / \mathrm{kg})$ & 24 & $22.5 / 27$ & 24 & $19.5 / 28.5$ & 0.562 \\
\hline & $180^{\circ} / \mathrm{sec}$ ER/IR & 47 & $42 / 57.5$ & 54 & $46 / 69$ & 0.258 \\
\hline
\end{tabular}

DB: Deaf Basketball, HB: Healty Basketball, Dom: Dominant, Non-dom: Non dominant, ER: External Rotator, IR: Internal Rotator, Statistically significant difference $(\mathrm{p}<0.05)$

Table 3. Strength comparison of the dominant and non-dominant shoulders of DB players

DEAF BASKETBALL GROUP

\begin{tabular}{|c|c|c|c|}
\hline & Dominant (Median IQR) & Non-dominant (Median IQR) & $\mathbf{p}$ \\
\hline $60^{\circ} / \mathrm{sec}$ IR $(\mathrm{Nm} / \mathrm{kg})$ & $63(58.5 / 66)$ & $57(54 / 61.5)$ & $0.022 *$ \\
\hline $60^{\circ} / \mathrm{sec} \operatorname{ER}(\mathrm{Nm} / \mathrm{kg})$ & $30(30 / 33)$ & $33(28.5 / 33)$ & 0.589 \\
\hline $60^{\circ} /$ sec ER/IR & $51(47 / 56)$ & $56(49.5 / 58)$ & 0.046* \\
\hline 180/sec IR (Nm/kg) & $51(48 / 57)$ & $54(45 / 57)$ & 0.360 \\
\hline $180^{\circ} / \mathrm{sec}$ ER $(\mathrm{Nm} / \mathrm{kg})$ & $24(24 / 27)$ & $24(22.5 / 27)$ & 0.414 \\
\hline $180^{\circ} / \mathrm{sec}$ ER/IR & $48(44.5 / 50)$ & $47(42 / 57.5)$ & 0.350 \\
\hline
\end{tabular}

ER: External Rotator, IR: Internal Rotator, Statistically significant difference $(\mathrm{p}<0.05)$

Upon the examination on the difference between the dominant and non-dominant sides of HB players, it was found that there was no difference in terms of $60 \% \mathrm{sec}$ ER/IR ratio, $180^{\circ} / \mathrm{sec} \mathrm{IR} \mathrm{Nm/kg}$ and ER/IR ratio (p>0.05, Table 4), whereas there

Table 4. Strength comparison of the dominant and non-dominant shoulders of HB players

HEALTHY BASKETBALL GROUP

\begin{tabular}{|c|c|c|c|}
\hline & Dominant (Median IQR) & Non-dominant (Median IQR) & $\mathbf{p}$ \\
\hline $60 \% / \mathrm{sec}$ IR $(\mathrm{Nm} / \mathrm{kg})$ & $63(58.50 / 72)$ & $57(49.5 / 64.5)$ & 0.044* \\
\hline $60 \% / \mathrm{sec}$ ER $(\mathrm{Nm} / \mathrm{kg})$ & $36(27 / 40.5)$ & $33(27 / 37.5)$ & $0.026 *$ \\
\hline $60 \% /$ sec ER/IR & $55(41.5 / 64)$ & $53(48 / 61)$ & 0.456 \\
\hline $180^{\circ} / \mathrm{sec}$ IR (Nm/kg) & $51(42 / 55.5)$ & $42(37.5 / 51)$ & 0.096 \\
\hline $180^{\circ} / \mathrm{sec}$ ER $(\mathrm{Nm} / \mathrm{kg})$ & $27(22.5 / 33)$ & $24(19.5 / 28.5)$ & 0.002* \\
\hline $180 \% /$ sec ER/IR & $56(49 / 66)$ & $54(46 / 69)$ & 0.753 \\
\hline
\end{tabular}

ER:External Rotator, IR:Internal Rotator, Statistically significant difference $(\mathrm{p}<0.05)$ 


\section{DISCUSSION}

Due to the sensory feedback they received while planning the study, we had expected that muscle strength and endurance in HB players would be better than that of DB players. But as a result of this comparative study on the shoulder muscle strength and endurance of $\mathrm{DB}$ and $\mathrm{HB}$ players, it was found that the strength and endurance of the players in the two groups were similar. There was not a difference between the groups in terms of demographic features. However, it was believed that the sport starting age may have been delayed as a result of the medical treatments that the individuals in the DB group often had to receive because of the permanent drawback they had at an early age. Nevertheless, we still think that physical fitness levels are similar because they have a similar weekly training time.

Velocities up to $90^{\circ} / \mathrm{sec}$ are used for strength measurement with isokinetic systems, whereas $180^{\circ} / \mathrm{sec}-240^{\circ} / \mathrm{sec}$ velocity is generally preferred in endurance evaluation on the subjects. $60 \% \mathrm{sec}$ velocity is conventionally preferred in cases where strength evaluation is required in the shoulder joint while $180 \%$ sec is preferred in endurance evaluation (Brown, 2000). Therefore, evaluations in this study were performed at similar angular velocities. Previous studies have shown that the most reliable position in the shoulder muscle strength measurement of ER and IR, which can be performed in seated and standing positions, is indeed in a seated position with the arm in the scapular plane (Brown, 2000). Consequently, evaluations in this study were done in the seated position in the scapular plane. Evaluation results indicated that IR and ER muscle strength of the dominant and non-dominant extremities were similar between the groups at the velocities of $60^{\circ} / \mathrm{sec}$ and $180^{\circ} / \mathrm{sec}$. The fact that the DB group had similar shoulder muscle parameters suggested that auditory stimuli received from the environment did not affect the muscle strength parameters in the DB group despite the permanent drawback they sustained. Besides, having similar training time may have resulted in the absence of a difference in muscle strength despite their permanent drawback. In a study focusing on the effects of hearing loss on the performance of military personnel in combat with paintball simulation, it was found that hearing loss did not have any effect on the performance of surviving and winning despite the negative effects it had on the situational awareness of the individuals (Sheffield, Brungart, Tufts, \& Ness, 2017).

In the isokinetic evaluation of shoulders, ER/IR ratio is one of the most important criteria that determine a healthy glenohumeral joint function. In previous research, it has pointed out that differences in the ER/IR ratio, which is known to vary between $66-75 \%$ in healthy individuals, may cause musculoskeletal modification on the shoulders (Wilk et al., 2009). This, in turn, precipitates many shoulder pathologies, especially subacromial impingement (Burnham, May, Nelson, Steadward, \& Reid, 1993). Therefore, it may assist in the definition of strength profiles of orthopedic patients and athletes suffering from shoulder problems or the functional assessment of dynamic stability of muscle performance of the muscular structure of overhead throwing athletes (Codine et al., 2005; Dauty et al., 2003; P Edouard et al., 2009).

As a result of the evaluations, it was found that ER/IR ratios of dominant and non-dominant extremities of the DB and HB group at the angular velocity of $60 \% \mathrm{sec}$ were similar; however, ER/IR ratios of the DB group were lower than that of the $\mathrm{HB}$ group in the dominant extremity at the angular velocity of $180 \% \mathrm{sec}$ while they were similar in the non-dominant extremity at this velocity. ER/IR ratio, which is known to vary between $66-75 \%$ in healthy individuals, was lower than normal values in both groups, and this points out that they have a musculoskeletal injury risk. Since ER weakness against a strong IR will make the players more susceptible to injuries, it has been suggested that ER strengthening exercises should be included in their training programs. In a study on the prevention of overuse injuries of the shoulder on handball players, it was shown that a prevention program for strengthening ER in the dominant extremity reduced the shoulder injury rate by $28 \%$ (Andersson, Bahr, Clarsen, \& Myklebust, 2017). Therefore, studies suggest focusing on addressing and reducing such risk factors by decreasing harmful rotational glenohumeral adaptations and strengthening ER through neuromuscular and strength training programs (Cools, Johansson, Borms, \& Maenhout, 2015).

Comparison of the dominant and nondominant extremities of the individuals in the DB group showed that IR at $180 \% \mathrm{sec}$ angular velocity, ER at $60 \%$ sec angular velocity, ER and ER/IR ratios were similar. However, at $60 \% \mathrm{sec}$ angular 
velocity, IR muscle strength was found to be higher in the dominant extremity while ER/IR ratios were found to be significantly different between the two extremities. This difference in the ER/IR ratio between the two shoulders of the individuals in the DB group may be since IR strength is different in the two extremities. It has been stated in the studies that sport-specific musculoskeletal adaptations are present in atheletes who perform repeated overhead throwing activities (Hams, Evans, Adams, Waddington, \& Witchalls, 2019). The traditional movement profile of overhead athletes involves an increase in glenohumeral external rotation patency in the dominant extremity and a decrease in internal rotation (Hellem, Shirley, Schilaty, \& Dahm, 2019; Rose \& Noonan, 2018).

This excessive external rotation rate grants the glenohumeral joint a maximum internal rotation and consequently a maximum throw speed. Biomechanical studies have also shown that the increase in external rotation results in an increase in throw speed and IR torque in the internal rotation (Vogler et al., 2019). This is because the increase in the range of motion in external rotation will increase in the IR muscle length and muscle contraction strength. IR muscle strength on the dominant side may have turned out to be higher for this reason. Additionally, many studies on athletes have indicated that muscle strength is higher on the dominant extremity because it is the more commonly used extremity for throwing (Baltaci \& Tunay, 2004; Cibulka et al., 2015). Having found similar results on the dominant extremity, this study, therefore, seems to be consistent with the previous studies.

A separate comparison of the dominant and non-dominant extremities of the individuals in the HB group showed that there was no statistical difference between ER/IR ratios at $60^{\circ} / \mathrm{sec}$ angular velocity and IR and ER/IR ratio at $180^{\circ} / \mathrm{sec}$ angular velocity. However, statistically, it was found that ER and IR muscle strength at $60 \% \mathrm{sec}$ angular velocity was significantly higher on the dominant side, and ER muscle endurance at $180^{\circ} / \mathrm{sec}$ angular velocity was also significantly higher on the dominant side. Better strength and endurance values on the dominant side were expectedly consistent with the previous studies (Baltaci \& Tunay, 2004; Cibulka et al., 2015).

An overhead athlete's shoulder should be sufficiently balanced to allow for excessive external rotation, as well as to avoid subluxation of the humeral head (Vogler et al., 2019). Therefore, there is a need for a sophisticated balance between mobility and functional stability, including typical static (articular capsule, bone anatomy and labrum) and dynamic (rotator cuff, long upper-end tendons of the biceps muscle and scapulothoracic muscles) stabilizers. This is known as The Throwers Paradox (Vogler et al., 2019). The basic approach, in this case, is to eliminate muscular imbalance with the help of training programs to prevent musculoskeletal injuries. Despite the less frequent use of the non-dominant side, strengthening exercises should be performed on it as well to ensure a muscular balance for stabilization in case of a trauma.

The limitation of this study may be that we did not make performed a performance evaluation, although the force measurements provide information about performance. In future studies, besides the force measurements, performance measurements can also be made.

Results of this study have shown that shoulder IR and ER muscle strengths were similar in the individuals of the DB and HB groups; however, both groups were found to be at risk for musculoskeletal injuries with regards to ER/IR ratio. It has been considered that the addition of ER strengthening exercises in athlete training programs in order to eliminate the muscular imbalance between IR and ER muscles can reduce injury risk. Upon the separate evaluation of dominant and non-dominant extremities within themselves, it was seen that the strength of the dominant extremity muscles was generally higher. Hence, symmetrical muscle strength was found important in the maintenance of stability and avoidance of vertebral pathologies due to the intensity of movements in basketball that involve the use of both extremities at the same time. It was, therefore, concluded that improvement exercises for the strength of the non-dominant extremity should be performed because the achievement of symmetrical movement patterns and strength balance can have positive impacts. This study has, moreover, shown that deaf individuals can achieve similar muscle strength and endurance to that of healthy individuals as a result of well-planned training programs and consistent sports activities. 


\section{Conflict of interest}

The authors declare no conflict of interest. No financial support was received.

\section{REFERENCES}

Akçakaya, İ. (2009). Trakya Üniversitesi futbol, atletizm ve basketbol takımlarındaki sporcularin bazı motorik ve antropometrik özelliklerinin karsılastırılması.

Akınoğlu, B., \& Kocahan, T. (2017). Characteristics of upper extremity's muscle strength in Turkish national wheelchair basketball players team. Journal of exercise rehabilitation, 13(1), 62.

Andersson, S. H., Bahr, R., Clarsen, B., \& Myklebust, G. (2017). Preventing overuse shoulder injuries among throwing athletes: a cluster-randomised controlled trial in 660 elite handball players. $\mathrm{Br} J$ Sports Med, 51(14), 1073-1080.

Baltaci, G., \& Tunay, V. B. (2004). Isokinetic performance at diagonal pattern and shoulder mobility in elite overhead athletes. Scandinavian journal of medicine \& science in sports, 14(4), 231-238.

Berckmans, K., Maenhout, A. G., Matthijs, L., Pieters, L., Castelein, B., \& Cools, A. M. (2017). The isokinetic assessment of rotator cuff strength ratios and the effect of an exercise program on these ratios in overhead athletes: A systematic literature review. Physical Therapy in Sport.

Brancaleone, M. P., Shingles, R. R., \& DeLellis, N. (2017). Deaflympians' Satisfaction With Athletic Training Services at the 2013 Deaflympic Summer Games. Journal of athletic training.

Brown, L. E. (2000). Isokinetics in human performance: Human Kinetics.

Burnham, R. S., May, L., Nelson, E., Steadward, R., \& Reid, D. C. (1993). Shoulder pain in wheelchair athletes: the role of muscle imbalance. The American journal of sports medicine, 21(2), 238-242.

Cibulka, M. T., Enders, G., Jackson, A., Maines, S., Von der Haar, J., \& Bennett, J. (2015). The relationship between passive glenohumeral total rotation and the strength of the internal and external rotator muscles, a preliminary study. International journal of sports physical therapy, 10(4), 434.
Codine, P., Bernard, P., Pocholle, M., \& Herisson, C. (2005). Isokinetic strength measurement and training of the shoulder: methodology and results. Annales de readaptation et de medecine physique: revue scientifique de la Societe francaise de reeducation fonctionnelle de readaptation et de medecine physique, 48(2), 80-92.

Cools, A. M., Johansson, F. R., Borms, D., \& Maenhout, A. (2015). Prevention of shoulder injuries in overhead athletes: a science-based approach. Brazilian journal of physical therapy(AHEAD), 00-00.

Dauty, M., Delbrouck, C., Huguet, D., Rousseau, B., Potiron-Josse, M. a., \& Dubois, C. (2003). Reproducibility of concentric and eccentric isokinetic strength of the shoulder rotators in normal subjects 40 to 55 years old. Isokinetics and Exercise Science, 11(2), 95-100.

Dvir, Z. (2004). Isokinetics: muscle testing, interpretation, and clinical applications: Elsevier Health Sciences.

Edouard, P., Frize, N., Calmels, P., Samozino, P., Garet, M. a., \& Degache, F. (2009). Influence of rugby practice on shoulder internal and external rotators strength. International Journal of Sports Medicine, 30(12), 863-867.

Edouard, P., Samozino, P., Julia, M., Cervera, S. G., Vanbiervliet, W., Calmels, P., \& Gremeaux, V. (2011). Reliability of isokinetic assessment of shoulder-rotator strength: a systematic review of the effect of position. Journal of sport rehabilitation, 20(3), 367-383.

Ellenbecker, T. S., \& Davies, G. J. (2000). The application of isokinetics in testing and rehabilitation of the shoulder complex. Journal of athletic training, 35(3), 338.

Güzel N, Kafa N. (2016). Engellilerde Spor ve Siniflandırma, (pp. 135-156). Ankara: Gazi Kitabevi.

Hams, A. H., Evans, K., Adams, R., Waddington, G., \& Witchalls, J. (2019). Shoulder internal and external rotation strength and prediction of subsequent injury in water-polo players. Scandinavian journal of medicine \& science in sports.

Hellem, A., Shirley, M., Schilaty, N., \& Dahm, D. (2019). Review of Shoulder Range of Motion in the Throwing Athlete: 
Distinguishing Normal Adaptations from Pathologic Deficits. Current reviews in musculoskeletal medicine, 1-10.

Kurková, P., Válková, H., \& Scheetz, N. (2011). Factors impacting participation of European elite deaf athletes in sport. Journal of Sports Sciences, 29(6), 607-618.

Moraes, G. F., Faria, C. D., \& Teixeira-Salmela, L. F. (2008). Scapular muscle recruitment patterns and isokinetic strength ratios of the shoulder rotator muscles in individuals with and without impingement syndrome. Journal of Shoulder and Elbow Surgery, 17(1), S48-S53.

Pojskić, H., Šeparović, V., Užičanin, E., Muratović, M., \& Mačković, S. (2015). Positional role differences in the aerobic and anaerobic power of elite basketball players. Journal of human kinetics, 49(1), 219-227.

Pontaga, I., \& Zidens, J. (2014). Shoulder rotator muscle dynamometry characteristics: side asymmetry and correlations with ballthrowing speed in adolescent handball players. Journal of human kinetics, 42(1), 41-50.

Rose, M. B., \& Noonan, T. (2018). Glenohumeral internal rotation deficit in throwing athletes: current perspectives. Open access journal of sports medicine, 9, 69.

Ross, M. D., Irrgang, J. J., Denegar, C. R., McCloy, C. M., \& Unangst, E. T. (2002). The relationship between participation restrictions and selected clinical measures following anterior cruciate ligament reconstruction. Knee Surgery, Sports Traumatology, Arthroscopy, 10(1), 10-19.

Sheffield, B., Brungart, D., Tufts, J., \& Ness, J. (2017). The effects of elevated hearing thresholds on performance in a paintball simulation of individual dismounted combat. International journal of audiology, 56(sup1), 34-40.

Vogler, T., Schorn, D., Gosheger, G., Kurpiers, N., Schneider, K., Rickert, C., . . . Liem, D. (2019). Adaptive Changes on the Dominant Shoulder of Collegiate Handball PlayersA Comparative Study. The Journal of Strength \& Conditioning Research, 33(3), 701-707.
Warner, J. J., Micheli, L. J., Arslanian, L. E., Kennedy, J., \& Kennedy, R. (1990). Patterns of flexibility, laxity, and strength in normal shoulders and shoulders with instability and impingement. The American Journal of Sports Medicine, 18(4), 366375.

Wilk, K. E., Obma, P., Simpson, C. D., Cain, E. L., Dugas, J., \& Andrews, J. R. (2009). Shoulder injuries in the overhead athlete. Journal of orthopaedic \& sports physical therapy, 39(2), 38-54.

How to cite this article: Suner-Keklik, S., Cobanoğlu, G., Savaş, S. et al. (2020). Comparison of Shoulder Muscle Strength of Deaf and Healthy Basketball Players. Int J Disabil Sports Health Sci;3(1):20-27.

DOI: $10.33438 /$ ijdshs. 694943 